\title{
Ehrlichia muris sp. nov., Identified on the Basis of 16S rRNA Base Sequences and Serological, Morphological, and Biological Characteristics
}

\author{
BOHAI WEN, ${ }^{1}$ YASUKO RIKIHISA, ${ }^{1 *}$ JASON MOTT, ${ }^{1}$ PAUL A. FUERST, ${ }^{2}$ \\ MAKOTO KAWAHARA, ${ }^{3}$ AND CHIHARU SUTO ${ }^{4}$ \\ Department of Veterinary Pathobiology, ${ }^{1}$ and Department of Molecular Genetics, ${ }^{2}$ The Ohio State University, \\ Columbus, Ohio 43210, and Nagoya City Public Health Research Institute, Mizuho-ku, Nagoya 467, ${ }^{3}$ \\ and Department of Medical Zoology, Nagoya University School of \\ Medicine, Showa-ku, Nagoya $466,{ }^{4}$ Japan
}

\begin{abstract}
The 16S rRNA gene of a new infectious agent, strain $\operatorname{AS} 145^{\mathrm{T}}(\mathrm{T}=$ type strain), which was isolated from a wild mouse in Japan, was amplified by using the PCR. The amplimers were directly sequenced by dideoxynucleotide methods with Taq DNA polymerase. Sequence comparisons with other members of the tribe Ehrlichieae and related species revealed that the infectious agent isolated from the mouse is a new species of the genus Ehrlichia that is most closely related to Ehrlichia chaffeensis (level of sequence similarity, 97.9\%), an agent of human ehrlichiosis in the United States. This result was consistent with the results of an immunoblot analysis performed with immune sera against different ehrlichiosis agents. On the basis of these findings and other morphological, biological, and serological characteristics of the organism, we propose that ehrlichiae with these properties belong to a new species, Ehrlichia muris.
\end{abstract}

According to Bergey's Manual of Systematic Bacteriology (10a), the genus Ehrlichia includes four species that are the etiological agents of ehrlichiosis in dogs, horses, ruminants, and humans. Recently, several additional Ehrlichia species have been isolated and/or identified (1a, 7). In 1983, an infectious agent designated strain AS145 ${ }^{\mathrm{T}}$ ( $\mathrm{T}=$ type strain) was isolated from the spleen of a wild mouse (Eothenomys kageus) in Japan (5). This organism was identified as a member of the genus Ehrlichia on the basis of the results of morphological and antigenic comparisons (5). Like members of other Ehrlichia spp., strain $\mathrm{AS} 145^{\mathrm{T}}$ is a small, gram-negative, pleomorphic, obligately intracellular bacterium (5). In laboratory mice, strain AS145 ${ }^{\mathrm{T}}$ causes severe clinical signs similar to those caused by Ehrlichia sennetsu or Ehrlichia risticii, including splenomegaly and lymphadenopathy (5). However, using serological cross-reactivity as determined by the indirect fluorescent-antibody (IFA) test and Western blot (immunoblot) analysis, Kawahara et al. found that strain AS145 ${ }^{\mathrm{T}}$ is more closely related to Ehrlichia canis (5). In addition, strain AS145 ${ }^{\mathrm{T}}$ forms tightly packed morulae in host cells, like $E$. canis does (5).

So far, strain $\mathrm{AS} 145^{\mathrm{T}}$ is the only ehrlichial strain that has been isolated from mice. In order to define the phylogenetic relationship between this organism and other ehrlichial species, the 16S rRNA gene of strain AS145 ${ }^{\mathrm{T}}$ was amplified by PCR and sequenced. In this paper we describe the results of a comparison of 16S rRNA sequences, a Western blot analysis, and tests to determine the susceptibility of dogs to strain $\mathrm{AS}_{145^{\mathrm{T}}}$. On the basis of our results, we propose that strain AS145 ${ }^{\mathrm{T}}$ should be considered a member of a new Ehrlichia species which is most closely related to Ehrlichia chaffeensis, a human ehrlichiosis agent, and somewhat less closely related to Ehrlichia ewingii and E. canis.

\footnotetext{
* Corresponding author. Mailing address: Department of Veterinary Pathobiology, College of Veterinary Medicine, 1925 Coffey Rd., Columbus, OH 43210-1093. Phone: (614) 292-9677. Fax: (614) 2926473 .
}

\section{MATERIALS AND METHODS}

Ehrlichia spp. and cell culture. Strain $\mathrm{AS} 145^{\mathrm{T}}$, E. chaffeensis, and E. canis were cultured in dog macrophage cell line DH82 in minimum essential medium (GIBCO, Grand Island, N.Y.) containing 10\% fetal bovine serum and $2 \mathrm{mM}$ L-glutamine in a $5 \% \mathrm{CO}_{2}$-air atmosphere (10). Strain $\mathrm{AS}_{145} 5^{\mathrm{T}}$ had been maintained previously by passage in mice (5). To culture strain $\mathrm{AS} 145^{\mathrm{T}}$ in $\mathrm{DH} 82$ cells, spleen cells from infected mice were overlaid on DH82 cell monolayers and cultured until the DH82 cells were infected. The infectious agents were purified from the host cells as previously described (10).

Extraction of DNA. Using a standard technique (6), we disrupted the bacterial cells with TE buffer (10 mM Tris, 1 mM EDTA; pH 8.0) containing 1\% sodium dodecyl sulfate (SDS). The DNA was extracted with phenol-chloroform and precipitated with ethanol.

Amplification of strain AS145 $^{\mathrm{T}}$ 16S rRNA. The 16S rRNA gene was amplified with 5' end primer ER5-3 (5'-TTGAGAGTTTGATCCTGG-3'), which is specific for all Ehrlichia species, most Rickettsia spp., and a few Rhodobacter spp., but no other members of the $\alpha$ subgroup of the purple bacteria, and $3^{\prime}$ end primer 3-17 (5'-AAGGAGGTAATCCAGCC-3'), a universal primer for the 16S rRNA sequences of prokaryotic cells. Genomic DNA and $50 \mathrm{pmol}$ of each primer were added to a $100-\mu l$ reaction mixture containing $10 \mu \mathrm{l}$ of $10 \times$ buffer, $5 \mu 1$ of $50 \mathrm{mM}$ $\mathrm{MgCl}_{2}, 2 \mu \mathrm{l}$ of a $10 \mathrm{mM}$ deoxynucleotide triphosphate mixture, and $2.5 \mathrm{U}$ of $\mathrm{Taq}$ DNA polymerase (GIBCO BRL, Gaithersburg, Md.). The reaction mixture was incubated at $94^{\circ} \mathrm{C}$ for $1 \mathrm{~min}$, at $55^{\circ} \mathrm{C}$ for $2 \mathrm{~min}$, and at $72^{\circ} \mathrm{C}$ for $3 \mathrm{~min}$, and this cycle was repeated 30 times. A DNA fragment of the expected size $(\sim 1.5 \mathrm{~kb})$ was purified from a $1 \%$ low-melting-temperature agarose gel (GIBCO BRL) by using a PCR DNA purification system (Promega, Madison, Wis.). The purified doublestranded DNA was kept at $-20^{\circ} \mathrm{C}$ for sequencing.

DNA sequencing of 16S rRNA. Sequencing was carried out by the dideoxynucleotide method, using a double-stranded DNA cycle sequencing system according to the instructions of the manufacturer (GIBCO BRL). The sequencing primers which we used were chosen by using the conserved sequences of the previously described ehrlichial 16S rRNA genes and the results of an OLIGO program (National Biosciences, Inc., Hamel, Mich.) analysis. The primers used for sequencing were primers ER5-3 (5'-TTGAGAGTTTGATCCTGG$\left.3^{\prime}\right)$, A325-332 (5'-CTACGGGAGGCAGCAGTG-3'), A769-776 (5'-TAGTC CACGCTGTAAACG-3'), A1048-1064 (5'-TAAGTCCCGCAACGAGC-3'), AR248-230 (5'-CATTACCTTACCAACTAAC-3'), AR494-477 (5'-GTATTAC CGCGGCTGCTG-3'), AR882-864 (5'-CCCCGTCAATTCCTTTGAG-3'), AR1158-1140 (5'-GACTTGACATCATCCCCAC-3'), and AR1454-1437 (5'-G CTACCTTGTTACGACTTC- $3^{\prime}$ ). The numbers in the designations of primers A325-332, A769-776, A1048-1064, AR248-230, AR494-477, AR822-864, AR1158-1140, and AR1454-1437 refer to locations in the 16S rRNA gene sequence of strain AS145 ${ }^{\mathrm{T}}$. The primers were end-labelled with $\left[\gamma^{32} \mathrm{P}\right] \mathrm{ATP}$ by using T4 kinase (GIBCO BRL). A 5\% Long Ranger gel (AT Biochem, Malvern, $\mathrm{Pa}$.) was used for sequencing in order to identify more than 400 bases with each primer. Both strands were sequenced with the forward and reverse primers to avoid the possibility of sequencing errors.

Computer analyses of DNA sequences. Sequences were aligned manually with 


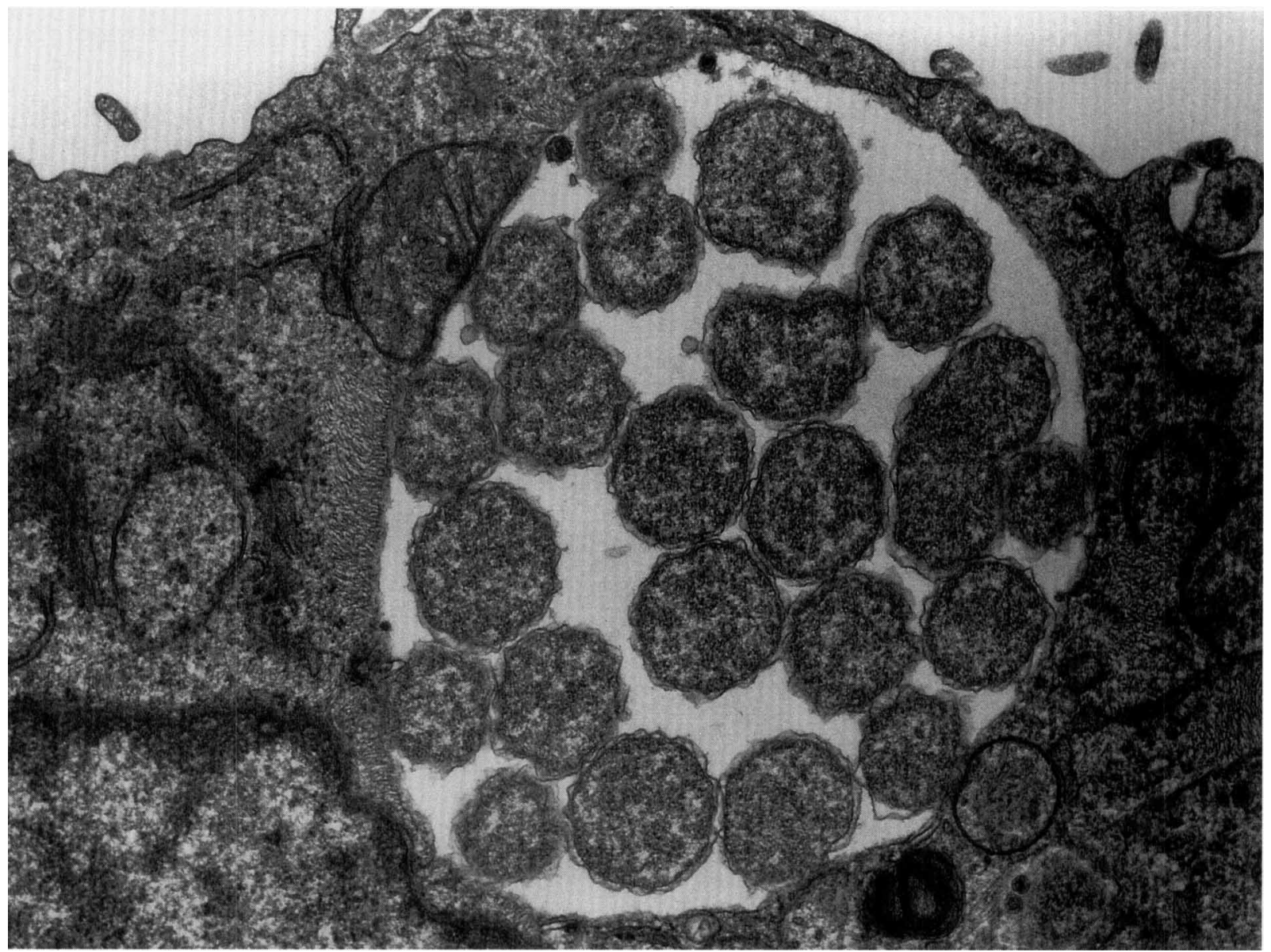

FIG. 1. Ultrastructure of strain AS145 ${ }^{\mathbf{T}}$ in DH82 cells. Note the multiple organisms in an inclusion (morulae). Magnification, $\times 16,000$.

the ESEE program (2). The corrected levels of nucleotide divergence of $16 \mathrm{~S}$ rRNA genes were calculated by using the DNADIST program in PHYLIP, version 3.1 (4), and the Kimura two-parameter correction. A phylogenetic tree was constructed by using the neighbor-joining method (NEIGHBOR in PHYLIP) (4) and data from the distance matrix. Only data for homologous sites at which alignment of $16 \mathrm{~S}$ rRNA gene sequences was unambiguous were included in the phylogenetic analysis. An alternative cladistic reconstruction of the phylogenetic relationships among taxa was obtained by using the parsimony program PAUP, version 3.1 (11).

Additional taxa. The following taxa were also used in this study: Cowdrio ruminantium, E. chaffeensis, E. canis, E. ewingii, Anaplasma marginale, "Ehrlichia bovis" (11a), "Ehrlichia platys", Ehrlichia phagocytophila, Ehrlichia equi, E. sennetsu, E. risticii, Neorickettsia helminthoeca, Wolbachia pipientis, and Rickettsia rickettsii. The nucleotide sequences of the $16 \mathrm{~S}$ rRNAs of these organisms were obtained from GenBank.

Western blot analysis. As previously described (9), the purified ehrlichial antigens were dissolved in $0.125 \mathrm{M}$ Tris- $\mathrm{HCl}(\mathrm{pH} 6.8)$ containing $2 \%$ SDS, $10 \%$ glycerol, and $5 \% \beta$-mercaptoethanol by heating the preparation at $100^{\circ} \mathrm{C}$ for 5 min, and samples ( $40 \mu \mathrm{g}$ of protein per lane) were separated by SDS-polyacrylamide gel electrophoresis on a $12 \%$ polyacrylamide slab gel; the separated antigens in the gel were transferred to a nitrocellulose membrane with an electrotransblotter (Enprotech, Hyde Park, Mass.) at a constant current of $100 \mathrm{~mA}$ for $45 \mathrm{~min}$. The membrane was blocked with $5 \%$ milk in phosphate-buffered saline and then incubated with anti-strain $\mathrm{AS}^{145^{\mathrm{T}}}$ mouse serum (homologous titer, 1:1,200; used at a dilution of 1:50), anti-E. chaffeensis human serum (homologous titer, 1:1,024; used at a dilution of 1:50), anti-E. canis dog serum (homologous titer, 1:5,120; used at a dilution of 1:50) and anti-E. ewingii dog serum (homologous titer not available because of our inability to culture $E$. ewingii; used at a dilution of $1: 50$ ) at $4^{\circ} \mathrm{C}$ overnight. After three rinses, the membrane was incubated with diluted $(1: 1,000)$ alkaline phosphatase-conjugated affinity-purified anti-dog, anti-mouse, or anti-human immunoglobulin $\mathrm{G}$ (Kirkegaard \& Perry Laboratories, Inc., Gaithersburg, Md.) at room temperature for 2 h.

Analysis of dogs experimentally infected with strain $\mathbf{A S 1 4 5}^{\mathrm{T}}$. Three 1- to 2-year-old German Shepherd-mixed breed dogs were purchased from Biomed- ical Associates, Inc., Friedensburg, $\mathrm{Pa}$. The dogs were either colony bred or originally acquired at a pound by Biomedical Associates after health certification by a veterinarian and a rabies vaccination. These dogs had been quarantined for more than 1 year in the Biomedical Associates facility. During the quarantine period, each dog was vaccinated according to the manufacturer's instructions against distemper, hepatitis, parvovirus infection, and leptospirosis, and several dewormings were performed according to the manufacturer's instructions. The dogs weighed 40 to $70 \mathrm{lb}(18$ to $32 \mathrm{~kg}$ ) when the study began. At 15 days before the experiment and on the day of the experiment, all of the dogs were seronegative for strain $\mathrm{AS}_{145^{\mathrm{T}}}$ or $E$. canis, as determined by the IFA test (10). Each dog was inoculated intravenously with $10^{7}$ strain AS145 ${ }^{\mathrm{T}}$-infected DH82 cells suspended in $5 \mathrm{ml}$ of minimum essential medium. Heparinized blood $(20 \mathrm{ml})$ was collected from the jugular vein weekly to monitor specific antibody titers, complete cell counts, and the presence of strain $\mathrm{AS} 145^{\mathrm{T}}$ in the blood.

IFA test and culture of strain AS145 ${ }^{\mathrm{T}}$. Antibody titration of serum and plasma specimens from dogs exposed to strain $\mathrm{AS} 145^{\mathrm{T}}$ was performed by an IFA test in which we used acetone-fixed strain AS145 ${ }^{\mathrm{T}}$ cultured in DH82 cells as the antigen. The presence of ehrlichiae in the blood was determined by overlaying mononuclear cell fractions obtained with Histopaque 1077 (Sigma Chemical Co., St. Louis, Mo.) on DH82 cell monolayers and culturing them for up to 2 months as described previously (10).

Electron microscopy of strain AS145 ${ }^{\mathrm{T}}$. Strain AS145 ${ }^{\mathrm{T}}$ cells cultured in DH82 cells were fixed overnight at $4^{\circ} \mathrm{C}$ in a mixture consisting of $5 \%$ glutaraldehyde, $2.5 \%$ paraformaldehyde, and $0.03 \%$ trinitrophenol in $0.1 \mathrm{M}$ sodium cacodylate buffer ( $\mathrm{pH} 7.4$ ). The cells were washed twice with $0.1 \mathrm{M}$ cacodylate buffer, postfixed with $1 \%$ osmium tetroxide in $1.5 \%$ potassium ferrocyanide for $1 \mathrm{~h}$, block stained in $1 \%$ uranyl acetate, dehydrated in a graded series consisting of ethanol and propylene oxide, and embedded in Poly/Bed 812 resin (Polysciences, Inc., Warrington, Pa.). Ultrathin sections were stained with uranyl acetate and lead citrate and examined with a Philips model 300 electron microscope at $60 \mathrm{kV}$.

Nucleotide sequence accession numbers. The GenBank nucleotide sequence accession numbers for the $16 \mathrm{~S}$ rRNAs used for comparison in this study are as follows: C. ruminantium, X62432; E. chaffeensis, M73222; E. canis, M73221; E. ewingii, M73227; A. marginale, M60313; “E. bovis", U03775; $E$. platys, M82801; $E$. phagocytophila, M73220;E. equi, M73223; E. sennetsu, M73225; E. risticii, 
M21290; N. helminthoeca, U12457; W. pipientis, X61768; and $R$. rickettsii, M21293. The nucleotide sequence of strain AS145 ${ }^{\mathrm{T}}$ 16S rRNA has been deposited in the GenBank data library under accession number U15527.

\section{RESULTS}

Electron microscopy of strain AS145 ${ }^{\mathrm{T}}$. Strain $\mathrm{AS} 145^{\mathrm{T}}$ had been maintained previously by passage in mice. In this study, this organism was cultured for the first time in a continuous cell line. Electron microscopy revealed that the ultrastructure of strain $\mathrm{AS}_{145^{\mathrm{T}}}$ in DH82 cells, which are canine macrophages, was similar to the ultrastructure in mouse peritoneal macrophages (Fig. 1).

Analysis of the 16S rRNA sequence. A single $(\sim 1.5-\mathrm{kb})$ amplified product was obtained from strain $\mathrm{AS} 145^{\mathrm{T}}$ genomic DNA when the flanking primers ER5-3 and 3-17 were used. This PCR product was purified from the gel and used as the sequencing template. A sequence that was 1,428 bases long was obtained. The entire sequence of strain $\mathrm{AS} 145^{\mathrm{T}}$ was aligned with the 16S rRNA gene sequences of 12 species belonging to the tribe Ehrlichieae and with the sequences of the intracellular bacteria $R$. rickettsii and Rickettsia prowazekii. The highest levels similarity were found between the strain AS145 ${ }^{\mathrm{T}}$ sequence and the sequences of $E$. chaffeensis (level of sequence similarity, $97.9 \%), E$. ewingii $(97.5 \%)$, and $E$. canis $(96.9 \%)$. The strain $\mathrm{AS} 145^{\mathrm{T}}$ sequence also exhibited $96.7 \%$ sequence similarity with the $C$. ruminantium sequence. Comparisons with all other ehrlichial 16S rRNA gene sequences revealed levels of sequence similarity of less than $93 \%$. For further phylogenetic analysis with a computer program, we used a 1,400-base portion of the $16 \mathrm{~S}$ rRNA gene sequence which could be unambiguously aligned for all species. The levels of sequence similarity and corrected evolutionary distances used for phylogenetic comparisons are shown in Table 1 . There was no significant difference between the data in Table 1 and our manual comparison data. The phylogenetic tree obtained from these data is shown in Fig. 2. It is clear that strain AS145 $5^{\mathrm{T}}$ belongs to a distinct clade within the genus Ehrlichia and that this clade consists of E. chaffeensis, E. canis, E. ewingii, and C. ruminantium. Table 1 shows that the level of sequence similarity between strain $\mathrm{AS}_{145^{\mathrm{T}}}$ and its closest neighbor, $E$. chaffeensis, is greater than the levels of sequence similarity obtained in pairwise comparisons of several other Ehrlichia species, indicating that strain $\mathrm{AS} 145^{\mathrm{T}}$ represents a new distinct member of the genus Ehrlichia. Use of parsimony produced a branching order similar to that shown in Fig. 2. The significance of the branching order within the clade containing strain $A S 145^{\mathrm{T}}$ was determined by using the bootstrap procedure implemented in PHYLIP. Our results indicated that $C$. ruminantium diverged significantly from the other four members (bootstrap value, $84 \%$ ), but that no specific branching order of the remaining four species was significantly favored (all bootstrap values were $<60 \%$ ). Additional sequence information from other genes will be necessary to determine the exact branching order of the species within this four-species clade.

Immunoblot analysis. Using mouse antiserum to strain $\operatorname{AS} 145^{\mathrm{T}}$, we found that five polypeptides $(26,47,65,68$, and 74 $\mathrm{kDa}$ ) were shared by $E$. chaffeensis and strain AS145 ${ }^{\mathrm{T}}$; only one major polypeptide $(30 \mathrm{kDa})$ was shared by $E$. canis and strain $\operatorname{AS}^{145^{T}}$ (Fig. 3E). When we used dog anti-E. canis serum, we found that three polypeptides $(28,30$, and $47 \mathrm{kDa})$ were present in all three organisms, four additional polypeptides $(40,65,68$, and $74 \mathrm{kDa})$ were present in both $E$. chaffeensis and strain $\mathrm{AS} 145^{\mathrm{T}}$, and two different polypeptides (80 and 110 $\mathrm{kDa}$ ) were present in both $E$. canis and strain AS145 ${ }^{\mathrm{T}}$ (Fig. $3 \mathrm{D})$. When human anti-E. chaffeensis serum was used, we

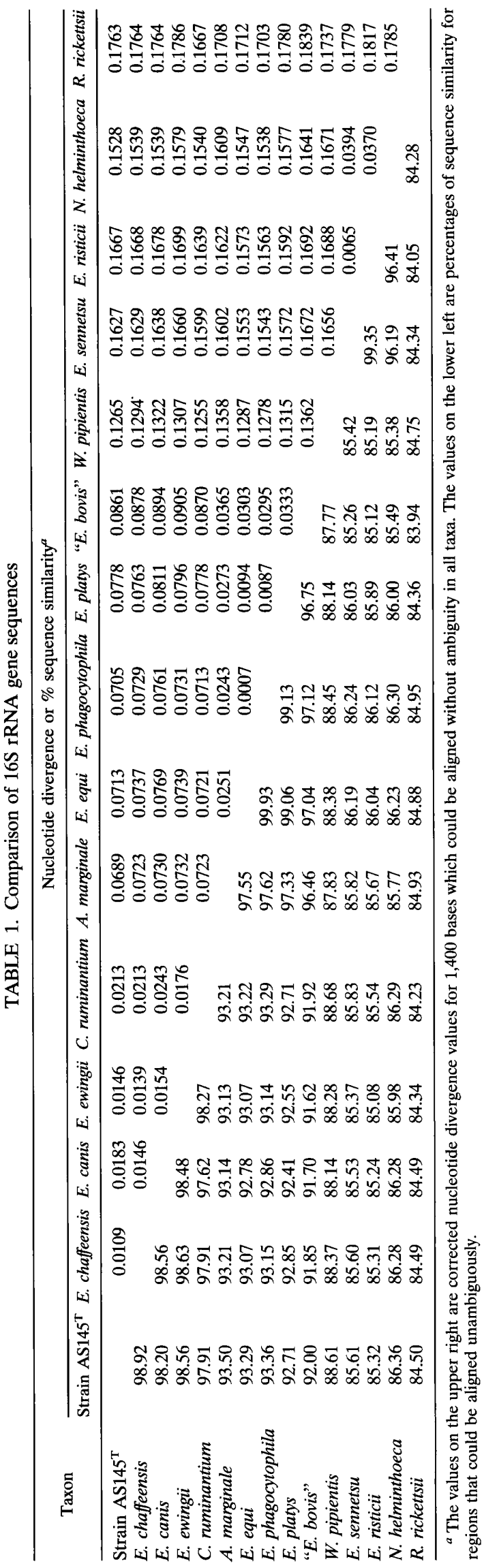




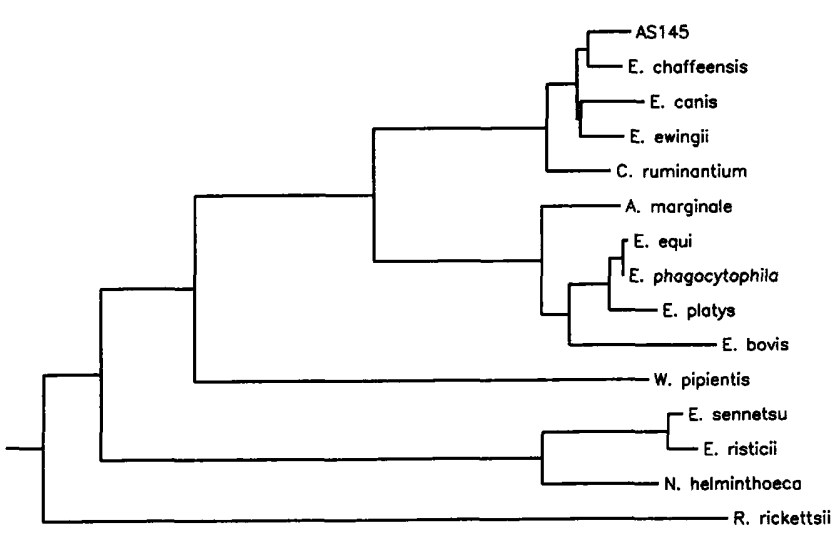

$\overline{2 \% \text { divergence }}$

FIG. 2. Phylogenetic relationships between strain $\mathrm{AS} 145^{\mathrm{T}}$ and other members of the tribe Ehrlichieae. A neighbor-joining tree was constructed by using the NEIGHBOR program in PHYLIP and the corrected nucleotide divergence values shown in Table 1. The level of sequence differentiation between a pair of species can be determined by adding the horizontal distances from the common ancestral node. The root was determined by considering other members of the alpha subgroup of the Proteobacteria.

found that three predominant proteins $(47,68$, and $74 \mathrm{kDa})$ were present in all three organisms and that additional weaker protein bands $(40,45,50$, and $70 \mathrm{kDa})$ were present in both $E$. chaffeensis and strain AS145 ${ }^{\mathrm{T}}$ preparations (Fig. 3C). A few additional weak bands were observed in both $E$. canis and $\mathrm{AS} 145^{\mathrm{T}}$ preparations. When dog anti-E. ewingii serum was used, three proteins $(47,68$, and $74 \mathrm{kDa})$ were found in all three organisms (Fig. 3B). No positive bands were found in uninfected DH82 cell lysate reacted with any of the four sera (Fig. 3A).

Clinical signs and immunologic responses of dogs inoculated with strain $\mathrm{AS}{ }^{\mathrm{T}}{ }^{\mathrm{T}}$. Strain $\mathrm{AS} 145^{\mathrm{T}}$ did not establish an infection in any of the experimentally infected dogs, as determined by weekly cultivation of peripheral blood mononuclear cell fractions obtained from the dogs and the IFA test results obtained with the sera. Strain AS145 ${ }^{\mathrm{T}}$ was not reisolated from a mononuclear cell fraction obtained from any of the dogs in this experiment. The IFA test titers were negative throughout the 5 weeks of the experiment except at 3 weeks postinfection, when the homologous titer against strain $\operatorname{AS} 145^{\mathrm{T}}$ was 1:20. The rectal temperatures, appetites, attitudes, body weights, blood leukocyte counts, and thrombocyte counts were normal in the dogs inoculated with strain $\mathrm{AS} 145^{\mathrm{T}}$ throughout the study.

\section{DISCUSSION}

The 16S rRNA gene of bacteria is highly conserved (12). This gene can be conveniently amplified by PCR from a very small sample of genomic DNA by using primers based on highly conserved regions of the known 16S rRNA sequences. The 16S rRNA gene of strain AS145 ${ }^{\mathrm{T}}$ was amplified with a $5^{\prime}$ end primer specific for Ehrlichia spp. and the $3^{\prime}$ end universal primer for prokaryotic cells. Sequencing analysis of 16S rRNA has been recognized as a powerful tool for identifying new organisms, especially obligately intracellular parasites that are difficult to grow and purify large in enough numbers for biochemical and other genetic studies.

The results of a previous phylogenetic study of Ehrlichia spp. based on 16S rRNA sequences (1) indicated that the members of the genus Ehrlichia can be divided into three groups; group 1 contains $E$. canis, E. chaffeensis, and $E$. ewingii, group 2 contains E. equi, E. phagocytophila, E. platys, and "E. bovis", and group 3 contains $E$. risticii, E. sennetsu, and $N$. helminthoeca (7). Our analysis of 16S rRNA sequences of Ehrlichia spp. showed that strain AS145 ${ }^{\mathrm{T}}$ was a member of group 1, was most closely related to $E$. chaffeensis, and was also related to $E$. ewingii and $E$. canis. In our immunoblot analysis, the antigenic profile of strain $\mathrm{AS} 145^{\mathrm{T}}$ was more similar to that of $E$. chaffeensis than to that of E. canis. Although E. chaffeensis and E. canis have been reported to establish infections in dogs and

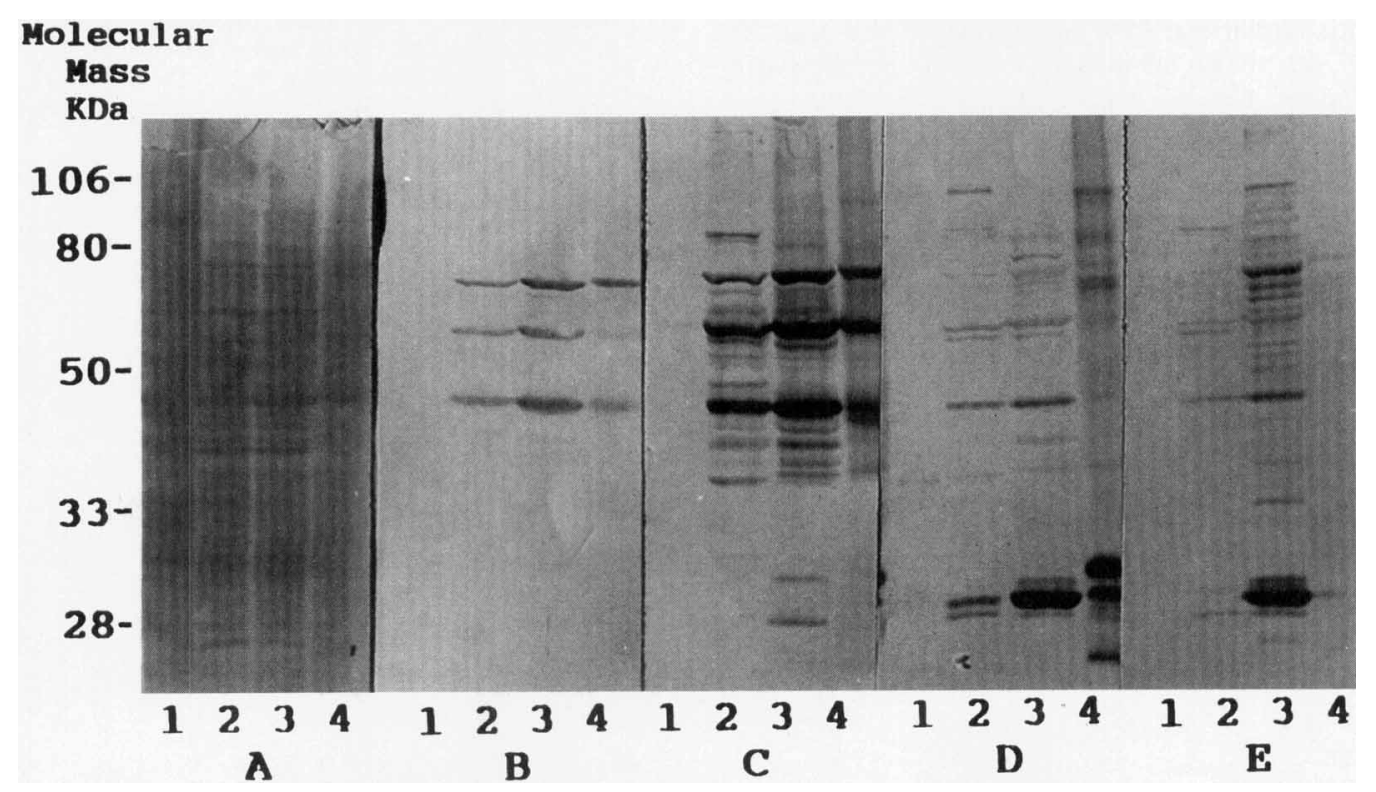

FIG. 3. Immunoblot analysis. The antigens used were DH82 (host cells) (lanes 1), E. chaffeensis (lanes 2), strain AS145 ${ }^{\mathrm{T}}$ (lanes 3), and E. canis (lanes 4). (A) Antigens stained with amido black. (B) Dog anti-E. ewingii immune serum. (C) Human anti-E. chaffeensis immune serum. (D) Dog anti-E. canis immune serum. (E) Mouse anti-AS145 ${ }^{\mathrm{T}}$ immune serum. 
to induce quick and strong humoral immune responses $(3,10)$, strain $\mathrm{AS}_{145^{\mathrm{T}}}$ was not able to establish infections in dogs.

Since the 16S rRNA gene is known to exhibit a high level of structural conservation and a slow evolutionary rate (12), levels of sequence difference greater than $0.5 \%$ for comparisons between complete or nearly complete sequences of members of the genus Ehrlichia have been considered sufficient to classify organisms in different species (1). The levels of difference which observed in pairwise comparisons of 1,428-base sequences of the 16S rRNA genes of strain AS145 and other members of the genus Ehrlichia ranged from 2.1 to $15.9 \%$. These results justify describing strain $\mathrm{AS} 145^{\mathrm{T}}$ as a member of a distinct Ehrlichia species.

Whether strain AS145 ${ }^{\mathrm{T}}$ infects human or nonhuman primates remains to be studied.

Description of Ehrlichia muris sp. nov. Ehrlichia muris (mu'ris. L. gen. n. muris, of a mouse; the species was first isolated from a mouse). Cells are gram-negative, pleomorphic cocci and vary in size, ranging from 0.4 to $1.5 \mu \mathrm{m}$ long and from 0.2 to $1.5 \mu \mathrm{m}$ in diameter. This organism can establish infections in mice when it is injected intraperitoneally and can cause severe clinical signs in laboratory mice, including splenomegaly and lymphadenopathy. Inclusion bodies are observed only in the cytoplasm of spleen and peritoneal macrophages of infected mice on smears stained by the Giemsa method. As determined by electron microscopy, small pleomorphic cocci within membrane-lined vacuoles occur in the cytoplasm of macrophages, and each organism is surrounded by a distinct cytoplasmic membrane and a rippled outer membrane without a distinct peptidoglycan layer.

E. muris grows in dog macrophage cell line DH82 in minimum essential medium containing $10 \%$ fetal bovine serum and $2 \mathrm{mM}$ L-glutamine in a $5 \% \mathrm{CO}_{2}$-air atmosphere at $37^{\circ} \mathrm{C}$. No growth occurs in the yolk sacs of chicken embryos.

Tetracyclines effectively prevent infection of mice, but penicillin and sulfonamides do not.

Serologically, $E$. muris is reciprocally cross-reactive with $E$. chaffeensis and $E$. canis and is weakly cross-reactive with $E$. sennetsu as determined by IFA and Western blot tests.

The sequence of a 1,428-base segment of the E. muris $16 \mathrm{~S}$ rRNA gene is most similar to the sequences of $E$. chaffeensis (level of sequence similarity, 97.9\%), E. ewingii (97.5\%), and $E$. canis $(96.9 \%)$; E. muris also exhibits $96.7 \%$ sequence similarity with $C$. ruminantium. Comparisons with the $16 \mathrm{~S}$ rRNA gene sequences of all other Ehrlichia species revealed levels of sequence similarity of less than $93 \%$.

The type strain of E. muris is strain AS145. E. muris has been deposited in the American Type Culture Collection as VR1411.

\section{ACKNOWLEDGMENTS}

This work was supported by research grant R01 AI33123 from the National Institutes of Health.

We thank Thomas Ozro MacAdoo, Virginia Polytechnic Institute and State University, Blacksburg, for advice concerning the name.

\section{REFERENCES}

1. Anderson, B. E., J. E. Dawson, D. C. Jones, and K. H. Wilson. 1991. Ehrlichia chaffeensis, a new species associated with human ehrlichiosis. J. Clin. Microbiol. 29:2838-2842

1a.Anderson, B. E., C. E. Greene, D. C. Jones and J. E. Dawson. 1992. Ehrlichia ewengii sp. nov., the etiologic agent of canine granulocytic ehrlichiosis. Int. J. Syst. Bacteriol. 42:299-302.

2. Cabot, E. L., and A. T. Beckenbach. 1989. Simultaneous editing of multiple nucleic acid and protein sequences with ESEE. Comput. Appl. Biosci. 5:233234.

3. Dawson, J. E., and S. A. Ewing. 1992. Susceptibility of dogs to infection with Ehrlichia chaffeensis, causative agent of human ehrlichiosis. Am. J. Vet. Res. 53:1322-1327.

4. Felsenstein, J. 1989. PHYLIP-phylogeny inference package (version 3.3). Cladistics 5:164-166.

5. Kawahara, M., C. Suto, Y. Rikihisa, S. Yamamoto, and Y. Tsuboi. 1993. Characterization of ehrlichial organisms isolated from a wild mouse. J. Clin. Microbiol. 31:89-96.

6. Moore, D. V. 1992. Preparation and analysis of DNA, p. 2.10-2.12. In F. M. Ausubel (ed.), Short protocols in molecular biology. Greene Publishing Associates, John Wiley \& Sons, New York.

7. Pretzman, C., D. Ralph, D. R. Stothard, P. A. Fuerst, and Y. Rikihisa. 1995. 16S rRNA gene sequence of Neorickettsia helminthoeca and its phylogenetic alignment with members of the genus Ehrlichia. Int. J. Syst. Bacteriol. 45: 207-211.

8. Rikihisa, Y. 1991. The tribe Ehrlichieae and ehrlichial diseases. Clin. Microbiol. Rev. 4:286-308.

9. Rikihisa, Y. 1991. Cross-reacting antigens between Neorickettsia helminthoeca and Ehrlichia species, shown by immunofluorescence and Western immunoblotting. J. Clin. Microbiol. 29:2024-2029.

10. Rikihisa, Y., S. A. Ewing, J. C. Fox, A. G. Siregar, F. H. Pasaribu, and M. B. Malole. 1992. Analysis of Ehrlichia canis and a canine granulocyte Ehrlichia infection. J. Clin. Microbiol. 30:143-148.

10a.Ristic, M., and D. L. Huxsoll. 1984. Tribe II. Ehrlichieae Philip 1957, $948^{\mathrm{AL}}$, p. 704-711. In N. R. Krieg and J. G. Holt (ed.), Bergey's manual of systematic bacteriology, vol. 1. Williams \& Wilkins, Baltimore.

11. Swofford, D. 1993. PAUP: phylogenetic analysis using parsimony, version 3.1.1. Illinois Natural History Survey, Champaign.

11a.Visser, E. S., and B. A. Allsopp. Unpublished data.

12. Woese, C. R. 1987. Bacterial evolution. Microbiol. Rev. 51:221-271. 